\title{
PRÁTICAS EDUCATIVAS FEMININAS NAS MEMÓRIAS DE MARIA PAES DE BARROS
}

\author{
PRÁCTICAS EDUCATIVAS FEMENINAS EN LAS MEMORIAS DE MARIA PAES DE \\ BARROS
}

\author{
FEMALE EDUCATIONAL PRACTICES IN THE MEMORIES OF MARIA PAES DE \\ BARROS
}

\author{
Maria Celi Chaves VASCONCELOS ${ }^{1}$ \\ Eveline Viterbo GOMES ${ }^{2}$
}

RESUMO: $O$ artigo tem como tema evidenciar as memórias sobre a educação reunidas no livro "No tempo de dantes" escrito por Maria Paes de Barros. A partir de suas reminiscências de infância e de juventude, o objetivo do estudo é analisar aspectos comuns à educação feminina no século XIX, descritos pela autora em sua narrativa autobiográfica. Em um plano mais específico, verificam-se agentes e experiências educacionais citados na rememoração da autora, tendo como cenário uma ainda diminuta São Paulo. Trata-se de uma pesquisa qualitativa histórico bibliográfica que tem como principal fonte as memórias publicadas de Maria Paes de Barros, localizadas na segunda metade do oitocentos, período do seu nascimento e de sua infância e juventude vividas em uma típica família da elite paulista. Diante dos escritos autobiográficos da autora, é possível depreender, no cotidiano urbano ou campestre em que viveu, as lições recebidas, a rotina rigorosa de estudos, o pouco tempo para brincadeiras e a existência de muitas regras e castigos, com a finalidade de torná-la detentora de uma "boa educação", semelhante à das mulheres que viveram no seu tempo e contexto.

PALAVRAS-CHAVE: Educação feminina. Memórias educacionais. Escrita autobiográfica. Maria Paes de Barros. Educação oitocentista.

RESUMEN: El tema del artículo es resaltar las memorias sobre educación recolectadas en el libro "No tempo de dantes" escrito por Maria Paes de Barros. A partir de sus reminiscencias de infancia y juventud, el objeto del estudio es analizar los aspectos comunes a la educación femenina en el siglo XIX, descritos por la autora en su narrativa autobiográfica. En un nivel más específico, hay agentes y experiencias educativas mencionados en la rememoración de la autora, teniendo como escenario la ciudad de São Paulo todavía diminuta. Se trata de una investigación cualitativa histórico-bibliográfica, que tiene como fuente principal las memorias publicadas de Maria Paes de Barros, ubicadas en la segunda mitad de los años mil ochocientos, periodo de su nacimiento y la infancia y

\footnotetext{
${ }^{1}$ Universidade do Estado do Rio de Janeiro (UERJ), Rio de Janeiro - RJ - Brasil. Professora Titular da Faculdade de Educação, atuando no Programa de Pós-Graduação em Educação (Proped/UERJ). Doutorado em Educação (PUC-Rio). Bolsista de Produtividade em Pesquisa do CNPq - Nível 2 e Bolsista do Programa Cientista do Nosso Estado - (FAPERJ). Prócientista UERJ. ORCID: https://orcid.org/0000-0002-3624-4854. Email: maria2.celi@gmail.com

${ }^{2}$ Universidade do Estado do Rio de Janeiro (UERJ), Rio de Janeiro - RJ - Brasil. Doutoranda no Programa de Pós-Graduação em Educação - (Proped/UERJ). Bolsista da Coordenação de Aperfeiçoamento de Pessoal de Nível Superior - (CAPES). ORCID: https://orcid.org/0000-0001-7467-4647. E-mail: evelinevg@yahoo.com.br
} 
juventud vividas en una familia típica de la élite paulista. A la vista de los escritos autobiográficos da autora, es posible percibir, en el cotidiano urbano o rural en el que vivió, las lecciones recibidas, la rigurosa rutina de estudio, el poco tiempo para jugar, y la existencia de muchas reglas y castigos, para que tuviera una "buena educación", similar a la de las mujeres que vivieron en su tiempo y contexto.

PALABRAS CLAVE: Educación femenina. Memoria educativa. Escrita autobiográfica. Maria Paes de Barros. Educación ochocentera.

ABSTRACT: The objective of this paper is to highlight the memories on education compiled in the book "No tempo de dantes", written by Maria Paes de Barros. Based on the reminiscences from the days of her childhood and youth, the objective of this study is to analyze common aspects of women's education in the 19th century, described by the author in her autobiographical narrative. On a more specific plane, it is possible to verify educational agents and experiences in the author's memoirs, with a still very small city of São Paulo as a backdrop. This is a qualitative historical and bibliographical survey whose main source is formed by the recollections published by Maria Paes de Barros, located in the latter half of the nineteenth century, the time of her birth and period of her childhood and youth as part of a typical family of the São Paulo elite. In the face of the author's autobiographical writings, it is possible to envisage within her daily life in an urban or rural setting, the lessons learned, the strict study routine, the little time for fun and games and the abundance of rules and punishment, with the objective of making of her a "well bred" woman, similar to those living in her time and context.

KEYWORDS: Women's education. Educational memory. Autobiographical writings. Maria Paes de Barros. Education in the eighteen hundreds.

\section{Introdução}

Maria Paes de Barros publicou, originalmente, o livro "No tempo de dantes" no ano de 1946. Trata-se de uma obra autobiográfica em que sua autora escreve reminiscências de sua infância e de sua juventude, na segunda metade do século XIX, época em que viveu com seus pais, na Província de São Paulo. As lembranças são encadeadas por uma série de narrativas que demonstram o contexto no qual ela nasceu e cresceu, recebendo o que denominou como as "marcas" de quem era, aos 94 anos de idade, quando editou suas memórias.

Nascida em 1851, Maria Paes de Barros pertencia à elite paulista. Na família, havia membros com títulos de nobreza, como o barão de Souza Queiroz e a Marquesa de Valença, seus tios. Ou, ainda, o barão de Piracicaba, pai de seu primo e marido, Antônio Paes de Barros. O avô era brigadeiro, o pai, comendador. A riqueza de sua família provinha da exportação agrícola das fazendas de cana-de-açúcar e de café, em cujas propriedades existiam, sob o domínio de seu pai, trabalhadores escravizados de origem africana e colonos 
alemães. Além disso, como era comum entre a elite econômica da época, envolviam-se diretamente na política. Seu pai atuou na Câmara de São Paulo. Seu marido chegou a senador já na República.

Maria Paes de Barros era a mais velha dentre os dez filhos que tiveram dona Felicíssima Campos Barros e o comendador Luís Antônio de Souza Barros. Ele, à época do enlace, levou consigo três filhas do seu primeiro casamento, dentre as quais se destacava Dindinha, a única dentre todos os irmãos e irmãs a ser nomeada em "No tempo de dantes". Em todo o livro são poucas às referências aos irmãos homens, as quais surgem somente em algumas páginas, para que sejam ressaltadas as diferenças entre a educação recebida pelas "manas" e pelos meninos, já que, quando crianças, todos estudavam juntos, na casa, sob as orientações de Dindinha e de Mademoiselle, a preceptora alemã. No entanto, os meninos, "quando cresciam", o que ocorria por volta dos dez anos, eram mandados a um colégio interno na Alemanha, enquanto as meninas continuavam os estudos no ambiente doméstico até que se casassem.

Era costume, por essa época, as famílias abastadas mandarem estudar na Europa os seus filhos. Muitos escolhiam a França; ele [o pai comendador], porém, preferiu enviar os seus à Alemanha, visto ter relações comerciais com importante firma de Hamburgo. Para lá seguiram, pois, os três rapazes mais velhos, tendo sido internados em colégios, enquanto as meninas estudavam com Mademoiselle (BARROS, 1998, p. 12).

Diante das memórias autobiográficas de Maria Paes de Barros, o objetivo central deste estudo é demonstrar as práticas educativas comuns às mulheres oitocentistas, presentes na obra "No tempo de dantes", considerando que essa mesma educação era oferecida a boa parte das filhas das elites, particularmente nas regiões habitadas pelos grandes fazendeiros do café, nas décadas próximas ao limiar entre o Império e a República. Em um plano mais específico, verificam-se as lições recebidas para tornar as meninas mulheres bem-educadas, assim como as regras e os relatos cotidianos que acompanhavam a formação feminina, transmitida pelas mulheres adultas da casa às mais jovens. Para tanto, os procedimentos metodológicos da pesquisa histórico bibliográfica em pauta têm como fonte e objeto a obra de reminiscências escrita por Maria Paes de Barros, com ênfase em seus relatos de experiências educacionais, entendendo-as envoltas ao processo de construção da memória feminina na maturidade por meio da escrita autobiográfica, como um ato de arquivar-se a si mesma (CUNHA, 2019). 


\section{Uma vida entre mulheres: a educação para feminilidade}

Figura 1 - Imagem da capa do livro "No tempo de dantes"

Fonte: Barros (1998)

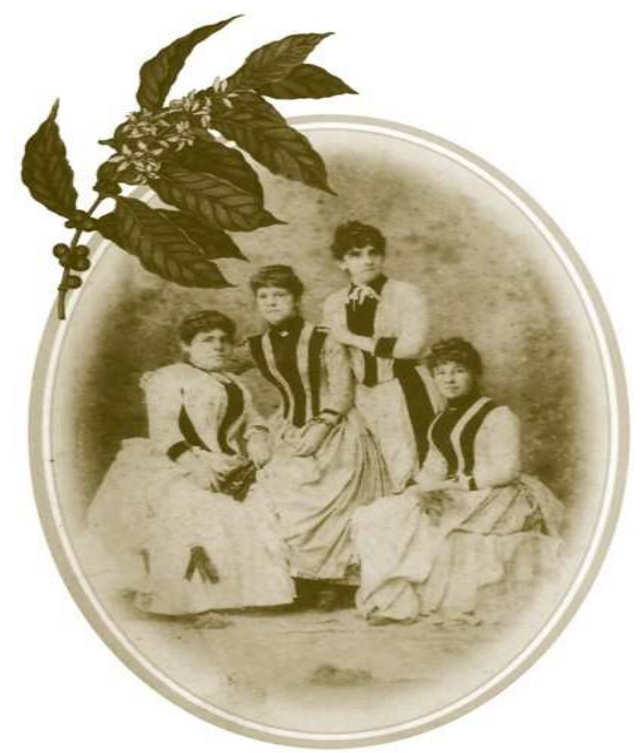

A fotografia apresentada na Figura 1 ilustra a capa da obra "No tempo de dantes" e foi tirada por volta do ano de 1875. Sua escolha como imagem de abertura do livro sugere a centralidade feminina nas memórias da autora, o que é reafirmado ao longo do texto nas interações com a preceptora, a irmã e a mãe, as quais assumiam o comando do espaço doméstico e, consequentemente, são as protagonistas das memórias. Como na maior parte das casas de elite oitocentistas, as meninas eram tornadas mulheres pelas mãos de outras mulheres (VASCONCELOS, 2018; FERRAZ, 2020). Tal fato não significa a ausência da figura masculina, pois toda a casa está sempre marcada pela forte presença masculina que a domina. Contudo, essa dominação faz algumas concessões às mulheres no que se refere à gestão do espaço doméstico. De acordo com Franco (2015, p. 72), “ao homem caberia o papel de principal administrador", já à mulher "cabia o papel específico de mulher e mãe, a par dos deveres e obrigações que se contraem na sociedade e para o recreio honesto, estabelecido entre as pessoas da sua classe". Assim, a mãe e, em sequência, as mulheres mais velhas da casa, eram responsáveis pela educação e o comportamento das mais jovens (LIÁÑEZ, 2019).

Nas memórias de Maria Paes de Barros a divisão entre a dominação masculina e a supervisão concedida à figura feminina estava concentrada naquela que é lembrada de forma elogiosa pela memorialista, Dindinha, a meia-irmã mais velha, que ajudaria na tarefa da educação das outras mulheres da casa (GOMES, 2018). 
É de se supor que a organização da família patriarcal do século XIX narrada pela autora encontra-se impregnada das ambiguidades que, decerto, caracterizavam as percepções de mundo de Maria Paes de Barros na maturidade, uma vez que, na escrita autobiográfica, as vivências do passado são reinterpretadas pelo próprio ator, nesse caso, atriz (ARFUCH, 2010). Essa imbricação entre passado e presente não significa um anacronismo ou um escamoteamento sobre "a verdadeira história de sua família", mas um processo natural da memória, conforme explica Rousso (2016, p. 41), quando as lembranças permitem "fazer reviver o passado no presente", tentar dar-lhe vida, pois que a "história não existe fora do pensamento que a produz e lhe dá forma após o acontecimento".

Nessa rememoração que vai ganhando forma e contexto, a autora assume o lugar de uma narradora onisciente e onipresente, mesclando as suas experiências com as das outras irmãs mais novas, para ressaltar as ações das mulheres adultas, identificadas como as vozes autorizadas para orientar, educar e formar a infância. Assim, as autoridades femininas são lembradas, inicialmente, pela definição da rotina imposta às crianças, que emerge do cotidiano da casa, e, a seguir, pelos traços de personalidade e funções bastante específicas atribuídas a cada uma delas.

Tratando-se de um "espaço de recordação" (ASSMANN, 2011), localizado em meio ao século XIX, as práticas educativas contadas e atribuídas às "mestras" da casa, envolviam muito mais do que simplesmente aprender signos e ensinamentos, mas era uma educação construída a cada momento, nos ambientes de convivência, nas festividades religiosas, nos passeios, nas viagens e, principalmente, nas situações de aprendizagem planejadas, organizadas e aplicadas, formalmente, por Dindinha e Mademoiselle, ou introduzidas, informalmente, por meio do compartilhamento das experiências domésticas de dona Felicíssima.

Dindinha, a irmã mais velha, é a grande referência de Maria Paes de Barros e a quem a autora atribui a sua educação, assim como a dos seus dez irmãos e irmãs mais novos. Foi ela quem ensinou às crianças as primeiras letras e a tocar piano, estabeleceu uma rotina de estudos na casa e listou os materiais didáticos a serem adquiridos, além de ter tido a iniciativa de introduzir outras habilidades no currículo das meninas, como a dança e o preparo para o casamento. Dindinha "dispunha, ordenava, fiscalizava e dirigia - tudo com grande proficiência e dedicação" (BARROS, 1998, p. 11).

Sob a austera rotina regida pelo soar de uma campainha, as crianças permaneciam sentadas no centro da sala de estudos, desde muito cedo até o horário do jantar, que era servido às 14 horas. Meninos e meninas reunidos em torno de uma grande carteira, rodeada 
por amplos mapas geográficos, estudavam lições em livros vindos diretamente da França. Enquanto os mais jovens aprimoravam o francês e os conhecimentos gerais a partir de biografias, histórias e relatos de viagens, as meninas mais velhas podiam desfrutar da "Revista Popular" e das novelas publicadas na coleção "L'Echo des Feuilletons". Com a dança, introduzida às moças por sugestão de Dindinha, que via nessa prática um eficiente meio de aquisição de boa postura corporal e de trejeitos delicados, as meninas recebiam aulas em casa, ministradas por duas ex-bailarinas italianas, e Dindinha as acompanhava tocando piano.

Ainda que fosse ela mesma a responsável pela educação dos irmãos e das irmãs, Dindinha fez, também, o que era habitual naquela época, e a família contratou uma preceptora, entre as muitas anunciadas pelos jornais para prestar seus serviços ensinando nas casas. De acordo com Vasconcelos (2018, p. 291):

[...] normalmente, eram recebidas em seus consulados ou mantinham alguma relação com eles, como demonstram muitos anúncios, desde os que facultavam o endereço oficial para a correspondência entre a candidata e seus contratantes, até os que davam informações sobre a pessoa que anunciava seus préstimos. Assim, aparecem constantemente, nos anúncios, o consulado francês, o consulado alemão, o consulado sueco, o consulado de Portugal e a agência cosmopolita.

Como era o desejo recorrente na elite oitocentista para a educação das filhas, a família Barros optou por uma preceptora alemã, embora Fraulein fosse chamada de Mademoiselle, tendo em vista que a língua fluente para ensinar era o francês (VASCONCELOS, 2018). Dessa forma, Dindinha e Mademoiselle constituíam a imagem típica das mulheres que atuavam na educação das crianças em uma casa da aristocracia brasileira na segunda metade do século XIX.

$\mathrm{Na}$ sala de estudos estavam as manas no seu elemento. Ali governava a Dindinha, com poder indiscriminado, e a Mademoiselle era o seu ídolo. Era afável e obsequiosa, soubera fazer-se querer e todos procuravam adivinharlhe os menores desejos. [...] Quem sabe se tal atitude não seria determinada por aspiração não realizada? [...] Sempre pronta a ajudar e prestar pequenos serviços, era quem planejava trabalhos e passeios que as manas executavam. Tornava-se, desse modo, objeto de geral carinho e estima a admirável Mademoiselle, como se fosse merecedora das afetuosas expansões que recebia com aquele amável sorriso (BARROS, 1998, p. 95).

A parceria entre Dindinha e Mademoiselle remonta ao modelo educacional bastante difundido entre as famílias da elite brasileira do século XIX. Uma educação privada, dada às crianças e jovens no interior da casa, de acordo com os interesses de seus pais, os quais tinham autonomia para escolher as disciplinas e os mestres envolvidos no processo. Segundo 
Vasconcelos $(2005 ; 2018 ; 2020)$, era comum as famílias recorrerem ao trabalho de preceptoras para educarem as filhas mulheres - e as estrangeiras eram consideradas, em uma hierarquia que privilegiava alemãs, francesas e inglesas, mas admitindo todas as nacionalidades desde que fossem fluentes em francês - as mais adequadas ao padrão de educação aspirado.

Mesmo após já estarem residindo no Brasil, os anúncios demonstram que as preferências das famílias eram por mulheres estrangeiras; o simples fato de ser alemã, francesa ou inglesa era referência suficiente das habilidades para a contratação (VASCONCELOS, 2018, p. 293).

As preceptoras encarregavam-se da educação de todas as crianças da casa até que os meninos tivessem idade para estudar em um colégio ou internato. Já as meninas ficavam sob seus cuidados, por vezes, até a idade que estivessem prontas para se casar. A casa da família Barros não fugia desse modelo: "Era realmente bem-dotada a professora: além de bonita, inteligente, culta e hábil em trabalhos manuais e misteres de cozinha, falava diversas línguas, tocava, cantava e desenhava bem" (BARROS, 1998, p. 12).

Outra memorialista, contemporânea de Maria Paes de Barros, também relembra a preceptora da sua casa, nesse mesmo período. Moradora da Província de São Paulo e nascida na década de 1870, Floriza Barboza Ferraz (2020), talvez influenciada pela publicação daquela autora (SOUZA, 2020, p. 269), escreve em 1947 suas "Páginas de recordações: memórias", obra na qual conta que sua irmã Júlia, "mandou vir da Europa uma professora muito instruída, chamava-se ela mademoiselle Luiza Neget" (FERRAZ, 2020, p. 64).

É interessante notar que mesmo reunindo as qualidades esperadas das preceptoras, especialmente de uma preceptora alemã, reconhecida pelo rigor com a disciplina, aos olhos de Maria Paes de Barros, Mademoiselle não era quem aplicava os castigos, "era tão indulgente que não gostava de puni-las quando erravam, dando-lhes apenas uma nota má no caderno. Quando a falta era maior, a Dindinha, sempre justiceira, era quem infligia o castigo" (BARROS, 1998, p. 96). Para a autora, entretanto, Dindinha era dotada de um grande "senso de justiça", entendido como equilíbrio perfeito entre "sensatez" e "firmeza". Em suas lembranças, esses atributos de Dindinha a tornavam um modelo para todas as mulheres, especialmente as mães, pois, com olhos vigilantes, acompanhava "todos os atos de suas vidas, atentos tanto à instrução como à educação moral e religiosa. Como meios auxiliares não faltavam, como já dissemos, os castigos, sempre julgados indispensáveis" (BARROS, 1998, p. 32). 
A temática das regras colocadas às crianças e as argumentações sobre a necessidade de imposição de limites a elas são retomadas por Maria Paes de Barros em momentos distintos do livro, assim como as lembranças dos castigos aplicados àqueles que às infringiam. Notadamente, a autora identificava nessas práticas ações fundamentais para a criação de adultos respeitosos, sendo considerado um aspecto positivo da educação recebida, que não havia abalado o clima de harmonia familiar constantemente rememorado por ela

Quanto a esse debate, Maria Paes de Barros situa no século XX a discussão acerca dos excessos dos castigos físicos infligidos às crianças, mas, de acordo com a sua percepção, no século XIX as famílias não comungavam dessas ideias, embora insista em demonstrar que não havia o uso da força física como método corretivo usual em sua casa (GOMES, 2016). Segundo ela, Dindinha recorria à suspensão do recreio quando a falta cometida era relativa às aulas: "As infrações às regras eram sempre punidas. Naquela época, os castigos faziam parte integrante do curriculum escolar" (BARROS, 1998, p. 14). Nos outros casos, aplicava lições moralizantes, as quais deveriam servir de exemplo para todos os irmãos e irmãs. Por isso, os castigos eram executados na hora do jantar. $\mathrm{O}$ desobediente deveria permanecer à mesa em silêncio, enquanto os outros saboreavam a sobremesa; podia ter cartazes presos à roupa ou era submetido a uma situação que o expusesse aos duros olhares dos presentes. Como exemplo, a autora conta o episódio em que uma das "manas" foi obrigada a esmolar, por ter sido impiedosa com uma velha senhora que pedia comida de porta em porta. Entretanto, contemporiza: “ainda que imposições vexatórias, não escandalizavam ninguém: eram sofridas pacientemente, como justas e naturais, e não constituíam nuvem que empanasse a felicidade das crianças, que viviam satisfeitas, rodeadas da afeição protetora dos pais" (BARROS, 1998, p. 53).

As casas da família Barros - tanto a da cidade como as das fazendas - configuravamse como o centro catalizador das experiências educacionais, espaços de conhecimento que estimulavam e propiciavam a produção intelectual (AGUIAR, 2015; 2020), cada qual com o seu potencial formativo. Aproveitavam-se todos os ambientes para as lições, a sala de estudos equipada com mapas, livros em francês e enciclopédias; o pomar onde as crianças podiam se divertir no intervalo das aulas; a sala de costuras; e a sala de jantar. Da mesma forma, é lembrado o entorno da casa grande e da senzala, de onde emergiram experiências eternizadas em sua memória, em um mundo que ela viu se modificar completamente, durante a transição entre os dois séculos em que viveu. 


\section{Acabada a educação é a hora de se casar: sensibilidades e obrigações femininas}

Figura 2 - Fotografia de cinco gerações de mulheres da família Souza Barros

Fonte: Barros (1998)

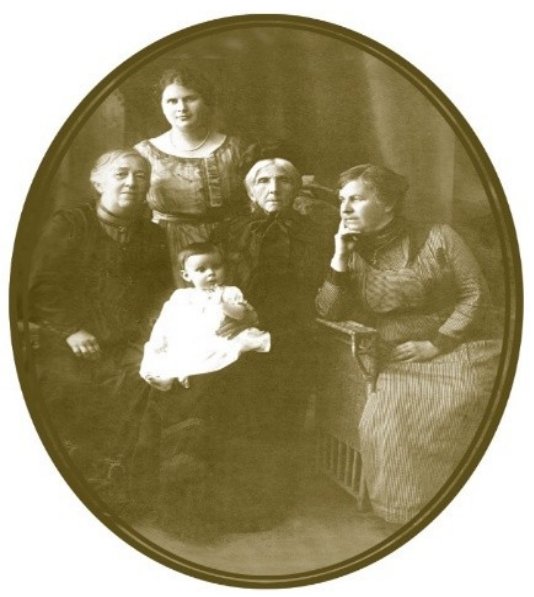

A Figura 2 mostra cinco gerações de mulheres da família de Maria Paes de Barros e foi tirada em 1920, quando ela já estava viúva e vinha sobrevivendo da direção de uma maternidade e da atuação como professora em uma escola presbiteriana (BARROS, 1998). A memorialista está à esquerda da fotografia, que tem ao centro sua mãe, dona Felicíssima, que também chegou a dar aulas nessa mesma escola como professora de piano. As outras duas mulheres são a filha (sentada), a neta (em pé) e a bisneta da autora (o bebê no colo da tataravó), o que evidencia a juventude com que as mulheres se casavam. "Saída apenas da sala de estudos para o casamento, sentia-se intimidada com tão grande contraste" (BARROS, 1998, p. 125). Com essa frase Maria Paes de Barros resume o percurso que era esperado de todas as mulheres da casa.

Segundo Bourdieu (2006), a narrativa biográfica desenvolvida como sequência linear e teleológica tende a introjetar no sujeito do passado características que o definem no presente. Tal prática acaba por construir uma representação da vida como um conjunto coerente, dotada de sentido prévio. Na perspectiva de Maria Paes de Barros, a infância tratava-se apenas de uma etapa que antecedia a vida adulta, ou seja, a única existente antes de se tornar mulher. Para uma menina, isso significava, basicamente, o período de preparação para o casamento, momento em que a jovem senhora colocaria em prática tudo o que aprendeu na casa da família, com as mulheres que a ensinaram. Para isso, não bastavam os conhecimentos aprendidos na sala de estudos, pois o casamento exigia ainda outras habilidades. Além de inteligente e culta, a senhora precisava ser "dona" de sua própria casa e não esquecer de evocar tudo o havia aprendido com as outras as mulheres de sua vida: 
Não era pequena a tarefa que tinha diante de si: governar, dirigir e, se preciso fosse até castigar as numerosas escravas que trabalhavam dentro de casa, todas mais velhas e mais práticas do serviço do que ela! [...] No entanto, não desanimava, nem perdia a alegria, pois tinha a mão forte do marido, que a orientava, e auxiliava em todas as dificuldades (BARROS, 1998, p. 126).

Uma parcela considerável das reminiscências da autora é ocupada pelas lembranças de sua mãe, dona Felicíssima, cumprindo papéis fundamentais para a família, como grande parceira do marido, pronta a animá-lo e a assumir suas responsabilidades; realizando tarefas domésticas com o auxílio das escravizadas que agiam ao seu comando; arrumando as bagagens; produzindo e reunido utensílios importantes para as longas viagens da família às muitas de suas fazendas. Nas lembranças da autora, dona Felicíssima conhecia todos os escravizados e os colonos pelo nome, escutava suas necessidades, orientava sobre a vida em família e manipulava ervas e medicamentos, "com o auxílio dos dois grossos volumes de 'Medicina Popular', de Chernoviz, curava-se muita gente" (BARROS, 1998, p. 66). Era, portanto, também a responsável por cuidar da saúde dos membros da família e da casa.

Não só na sua casa, como na administração, exercia ela as suas atividades. A senhora não somente ouvia e aconselhava, mas dirigia-se pessoalmente para a casa da administração, visitando a enfermaria das pretas e a dos pretos. Dotada de singular tino médico, ia aplicando cautelosamente os medicamentos, usando somente processos brandos - cataplasmas, fomentações e chás por ela mesma preparados (BARROS, 1998, p. 82).

Essa prática destinada às mulheres é também corroborada por Vasconcelos $(2018, \mathrm{p}$. 299), em estudo acerca da "Doutrina sobre o governo da casa", muito apreciada para a educação de mulheres nas últimas décadas do século XIX, como a escrita no livro de Adrien Sylvain, traduzida e publicada em capítulos na Revista Bazar Litterário ${ }^{3}$, na qual era afirmado que entre as funções da dona da casa estava zelar e cuidar da saúde de todos que nela habitassem.

Nessa perspectiva, é possível entrever uma certa autonomia das mulheres na definição das atividades de administração da casa. Dona Felicíssima destituía as escravizadas mais velhas e cansadas dos serviços pesados, nomeando para seus lugares as mais jovens. Antes, atestava a saúde de todas. Às adoentadas ficavam reservados os afazeres considerados mais leves, enquanto a saúde era restabelecida pela batata doce, mesmo "fortalecedor" que

${ }^{3}$ Conforme os Anais da Biblioteca Nacional, vol. 85, 1965, a revista quinzenal Bazar Litterário: de educação e de recreação foi publicada de $1^{\circ}$ de outubro de 1878 a 15 de junho 1879 , no Rio de Janeiro, pela Typographia de São Vicente de Paula. 
recomendava às crianças para evitar a morte prematura. Havia todo um "sistema doméstico" regido pelas mulheres, como descreve Carvalho (2008, p. 242):

\begin{abstract}
Um conjunto de regras que visa a estabelecer uma regularidade no trabalho da esposa, filhas e empregados. A sequência de atividades se concretiza em um conjunto de tarefas distribuídas em horários e dias preestabelecidos e supervisionados pela esposa. Fazem parte da rotina as atividades de manutenção, produção de objetos de decoração (trabalhos manuais), processamento e reposição de alimentos e a educação da filha para a reprodução dos saberes domésticos.
\end{abstract}

Tais conhecimentos eram aspirados por Maria Paes de Barros para que ela própria pudesse ser capaz de administrar a sua futura casa. No entanto, antes dela, as "manas" mais velhas chegaram na idade de se casar, o que fez com que o comendador desse início à busca por pretendentes. Procurava ser minucioso na análise, atentando para o menor sinal que fosse de "mescla de cor" na família do rapaz. Encontrado, logo era dispensado o candidato, corroborando o imenso preconceito existente naquele período. De toda forma, os principais indicados para o consórcio do casamento com as moças da família, eram, antes de todos, os parentes, seja para concentrar a riqueza, seja para não correr riscos com aventureiros desconhecidos. Assim, os noivos eram selecionados, normalmente, entre os membros da própria família, os primos, corroborando o que afirma Peñarrocha (2013, p. 232), de que "o casar-se, entendido como estratégia de reprodução social, resulta tão necessária para todo o grupo como reservada para tão somente uma pequena parte dentro dele" ${ }^{4}$, ou seja, antes de ser uma prática social, era também uma prática familiar recorrente.

Logo após o casamento das irmãs, Maria Paes de Barros, ainda bastante jovem, também se casou. Contava apenas dezesseis anos de idade, quando seu interesse considerado excessivo pelos livros, especialmente os de poesias amorosas, começaram a preocupar Dindinha, que logo convenceu-a a aceitar um pedido de casamento: "Não recuse essa felicidade!" (BARROS, 1998, p. 123). Chegara o momento da "melhor aluna da classe" se casar.

Apesar do destino ser o mesmo de suas irmãs - casar-se com um primo -, algo se colocava como distinto na trajetória da memorialista, pois ela nunca abandonou o seu envolvimento com os livros e a atenção aos estudos. Após anos de dedicação à casa e aos negócios da família, Maria Paes de Barros publicou a obra que escreveu durante um bom tempo e a alavancou entre os principais nomes da intelectualidade paulistana reunida no Instituto Histórico e Geográfico de São Paulo. Trata-se do livro "História do Brasil",

\footnotetext{
${ }^{4}$ Tradução livre do original em espanhol.
} 
publicado no ano de 1932. A essas tarefas, juntavam-se o interesse pelo ensino da disciplina de história e o entusiasmo pela educação, conforme destacou Caio Prado Júnior (BARROS, 1998, p. 14):

\begin{abstract}
Interessando-se inteligentemente pelo crescimento físico e espiritual de todos os de sua numerosa família, nela teve brilhante atuação. Nos serões de sua fazenda, às margens rumorejantes do Mogi-Guaçu, deliciava-se em ensinar História à juventude. Revivendo por narrativas dramatizadas os quadros do passado, aos olhos ávidos dos seus queridos desfilavam castelos cheios de idílios, cruzadas, torneios, caravelas... Visões que despertavam nos corações de seus netos e ouvintes aspirações nobres e anseios do infinito.
\end{abstract}

A autora continuou com o mesmo entusiasmo pela educação, mesmo quando suas condições financeiras já não eram favoráveis, restando apenas as lembranças dos anos de prosperidade. Entretanto, ainda assim, ela continuava acolhendo netos e amigos que necessitavam residir em São Paulo para estudar (PRADO JUNIOR in BARROS, 1998).

Cabe notar o destaque que Maria Paes de Barros dá ao casamento nos capítulos finais de sua obra memorialística, o que remete também à educação recebida, por diversos aspectos. Em uma complexa tecitura de representações, ela demonstra como deixou a meninice para se casar, tornar-se uma adulta, mas sempre carregando consigo a coletividade das mulheres que a formaram. Cada qual com suas características únicas e específicas,] deixaram na jovem senhora as marcas de si. De um lado, marcas importantes para a atuação na vida pública, de outro, os elementos para a construção de uma vida conjugal harmônica e feliz, como a que acreditou terem conhecido seus pais.

Outro aspecto evidenciado é que mesmo quando o casamento é a temática central, não faltam referências à irmã Dindinha e à preceptora alemã Mademoiselle, como lembranças que não se apagam das artífices do trabalho metódico, constante e persistente de formação daquela menina, transformada em mulher, e da aplicação que ela fez desses ensinamentos por toda a vida.

Assim, especialmente a mãe, dona Felicíssima, Dindinha e Mademoiselle, mas também outras personagens femininas que atuaram em seu processo de formação intelectual e nas práticas que aprendeu para a vida, são representadas sem nenhum traço de imperfeição, com uma descrição que pode ser inserida em um padrão mítico de família.

Kotre (1997) chama a atenção para o fato de que a mitificação não significa o falseamento da memória na maturidade, mas uma atitude que busca o conforto diante da perda, elaborando novas lembranças que invisibilizam as antigas. Ainda segundo o mesmo 
autor, esse é um processo pelo qual passamos ao enfrentar momentos de crise, que provocam marcos de readequação de nossas memórias.

Segundo Bourdieu (2006), essa perspectiva teleológica da narrativa biográfica é uma das "ilusões" da tipologia de escrita, chamada por ele de biografia ordinária, desenvolvida sob uma perspectiva totalizante da história de vida do sujeito, revelando uma narrativa linear e lógica. De fato, é nesse campo da escrita biográfica que se encontra "No tempo de dantes", no qual a autora tenta recuperar um todo coerente acerca da identidade que construiu no presente, a partir das influências recebidas, notadamente, das mulheres com as quais conviveu até a vida adulta. Ainda assim, trata-se de uma fonte privilegiada de entendimento das representações das práticas educativas femininas no oitocentos, justamente por evidenciar a perspectiva de quem viveu, bem como a reflexão sobre o que foi vivido, oferecendo uma reinterpretação da educação e do papel das mulheres na formação de outras mulheres.

À altura do ano de 1946, contando para além de noventa anos de idade, as personagens principais das reminiscências de Maria Paes de Barros já não estavam mais ao seu lado, nem a opulência e a riqueza daqueles tempos faziam parte do seu dia a dia. Do mesmo modo, a memorialista, depois de longos anos cuidando do marido enfermo, viu sua fortuna esvair-se. Talvez, a dura realidade dos últimos anos tenha iluminado com cores mais brandas as memórias relativas às pessoas que povoaram sua vida tantos anos antes: "E no fim da vida, quando a memória já não é fundamental para lidar com a realidade, ela pode se transformar na matéria prima da qual são feitos os sonhos" (KOTRE, 1997, p. 217).

\section{Considerações finais}

Ao escrever "No tempo de dantes", Maria Paes de Barros recorda da menina que foi, por meio de suas reminiscências, buscando no passado a mulher do seu presente, mesclada de si, de Dindinha, de Mademoiselle e de dona Felicíssima, um coletivo em uma única mulher. Foram elas que lhes deram as ferramentas necessárias para atravessar a vida, desde quando se viu na emergência de assumir a sua própria casa com o casamento, até as suas atitudes e comportamentos cotidianos, que, de alguma forma, permaneciam seguindo as vozes daquelas mulheres, cujo objetivo era educá-la para todas as sensibilidades e obrigações femininas daquele tempo e contexto.

Carretero $(2019$, p.918) afirma que "a educação da mãe na origem de nossas vidas e a projeção posterior, no âmbito público, do ensino daquelas pessoas que cultivavam e criavam um saber e/ou um saber fazer", configuraram-se, durante muito tempo, como ofícios 
essencialmente femininos, transmitidos entre mulheres, para dar continuidade à sabedoria acumulada ao longo dos anos, tão necessária para enfrentar os desafios da vida cotidiana. Contudo, o que Dindinha, Mademoiselle e dona Felicíssima não poderiam supor é que o mundo que elas imaginaram possível de ser ensinado e transmitido às mulheres de sua casa para exercerem seu papel na sociedade iria mudar completamente nas décadas seguintes e exigir outras práticas educativas femininas.

Caio Prado Júnior abre a introdução de "No tempo de dantes" com a seguinte sentença: "Certamente ainda está por se escrever o que a civilização deve à mulher" (PRADO JUNIOR in BARROS, 1998, p. XIII). Chamando atenção para a sua condição de mulher, o escritor enaltecia Maria Paes de Barros e sua contribuição para a "florescente civilização paulista”, não apenas por seu livro, escrito em um cenário que se afastava definitivamente do século XIX, mas, principalmente, pela sua atuação no campo da saúde, como diretora da Maternidade de São Paulo, colaboradora do Hospital Samaritano e fundadora do primeiro Tennis Club da cidade. Além disso, de acordo com o prefaciador, ao publicar uma "História do Brasil", em 1932, Maria Paes de Barros tornou-se reconhecida nacionalmente por seu trabalho historiográfico.

Mas é preciso discordar de Caio Prado Júnior. O destaque de Maria Paes de Barros, dentre tantas outras meninas da elite paulista que foram educadas na casa, está na obra que, segundo ele, foi escrita "para gáudio dos que se deleitam imaginando ambientes de outrora" (PRADO JUNIOR, 1998, p. 15). A autora, pela via da escrita autobiográfica, "No tempo de dantes", ousou dar vislumbre acerca do que "a civilização deve à mulher", rompendo, no gênero das escritas de si, com o absolutismo masculino dos autores e atores da história.

Em outra perspectiva, Loriga (2011, p. 69), relacionando biografia e história, demonstra que o acontecimento se desintegra imediatamente na multidão de imagens que o sucede, portanto, “o que se passa não contém nenhuma verdade em si e só tem sentido quando pensado e contado". Dessa forma, Maria Paes de Barros tanto se propôs a contar a história do Brasil em seu livro com esse título, quanto o fez "No tempo de dantes".

Como uma mulher representante de um tempo que não pode mais ser mais recomposto, a não ser pelos vestígios e memórias, ainda que idílicas, escritas como a de Maria Paes de Barros permitem que se perceba a importância das mulheres na formação de outras mulheres, sugerindo também que, tempos depois, será no próprio universo feminino que as mulheres ensinarão a outras a romper a ordem anterior.

A descrição de Maria Paes de Barros das mulheres mais relevantes da casa não as coloca numa vanguarda feminista. Afirmar isso seria incorrer em anacronismos. Na verdade, 
as representações de dona Felicíssima, Dindinha e Mademoiselle dizem muito mais sobre nossa nonagenária memorialista. Kotre (1997), em seus estudos sobre memória na maturidade, chama a atenção para o fato de ser difícil lembrarmos de como víamos o mundo no passado. No geral, o que lembramos está intimamente relacionado ao presente, ao momento em que recorremos às lembranças. Queremos, com isso, chamar a atenção para o quanto de presente há no passado (ROUSSO, 2016).

Quando Maria Paes de Barros expõe suas memórias, ela já não era o que foi na infância e na juventude. Não só pelas imposições biológicas, mas, especialmente, pelas sociais. A mulher oitocentista que vinha de uma família tradicional paulista, educada para ser esposa e mãe, viu sua fortuna dilapidada no novecentos e passou a atuar como professora. Escrever suas reminiscências significava um reencontro com sua identidade. Não um retorno, mas um reencontro. A autora mantinha uma relação realista com o seu presente, mas certamente readequou suas memórias aos novos rumos de sua vida, trazendo um pouco de passado para o presente, ainda que fosse sob a forma daquilo que aprendeu em casa de seus pais. Focar suas memórias na moradia paterna é, nas palavras de Arfuch (2013, p. 28), centrar a casa como "espaço/temporalidade", onde "as interações, os afetos, as rotinas, os trânsitos cotidianos" e as diferenças de gênero marcam também os ritmos da narrativa.

Embora haja em sua obra intensas alusões às imposições do patriarcalismo sobre a casa, são as ações femininas que preenchem grande parte das páginas, nas quais Maria Paes de Barros escreveu e deixou registradas suas reminiscências. Das lembranças da senhora atuante no século XX emergiram importantes evidências sobre a educação feminina praticada no oitocentos, pelas mulheres e para as mulheres. O pai, comendador, figurou nas memórias da autora apenas como a representação da autoridade, mas a mãe era a peça fundamental de toda a engrenagem senhorial, somando-se a ela Dindinha e Mademoiselle. Elas, as três, as únicas mulheres nomeadas, eram as protagonistas que, juntas, formavam a mulher ideal. Ideal para o século XIX. Ideal para as lembranças de um passado romantizado.

\section{REFERÊNCIAS}

AGUIAR, J. V. De palácio a museu: os espaços do conhecimento de Isabel e Leopoldina. In: Anuário do Museu Imperial. Petrópolis, RJ: Museu Imperial, 2020. v. 1, p. 103-122.

AGUIAR, J. V. Princesa Isabel e Leopoldina. Mulheres educadas para governar. Curitiba, PR: Appris, 2015. 
ARFUCH, L. Memoria y autobiografía. Exploraciones en los límites. Buenos Aires, Argentina: Fondo de Cultura Económica, 2013.

ARFUCH, L. O espaço biográfico. Dilemas da subjetividade contemporânea. Rio de Janeiro, RJ: EdUERJ, 2010.

ASSMANN, A. Espaços de recordação. Formas e transformações da memória cultural. Campinas, SP: Editora da Unicamp, 2011.

BARROS, M. P. No tempo de dantes. São Paulo, SP: Paz e Terra, 1998. BOURDIEU, P. A ilusão biográfica. In: AMADO, J; FERREIRA, M. M. F. (Org.). Usos e abusos da história oral. 8 ed. Rio de Janeiro, RJ: Editora FGV, 2006. p. 183-191.

CARVALHO, V. C. Gênero e artefato. O sistema doméstico na perspectiva da cultura material - São Paulo, 1870-1920. São Paulo, SP: Edusp, 2008.

CUNHA, M. T. S. (Des)Arquivar. Arquivos pessoais e ego-documentos no tempo presente. Florianópolis, SC: Rafael Copetti Editor, 2019.

SOUZA, M. M. Posfácio. In: FERRAZ, F. B. Páginas de recordações: memórias. São Paulo, SP: Chão Editora, 2020.

FRANCO, C. Casas das elites de Lisboa: objectos, interiores e vivências 1750-1830. Lisboa, Portugal: Scribe, Produções Culturais, Ltda, 2015.

GOMES, E. V. Condição feminina e educação nas memórias de Maria Paes de Barros. In: CONGRESSO INTERNACIONAL DE PESQUISA (AUTO)BIOGRÁFICA, 7., 2016, Cuiabá. Anais [...]. Cuiabá, MT: BIOgraph, 2016. Tema: Narrativas (auto)biográficas: conhecimentos, experiências e sentidos.

GOMES, E. V. Maria Paes de Barros: memórias de omissão em tempos de luta pela emancipação. In: CONGRESSO INTERNACIONAL DE PESQUISA (AUTO)BIOGRÁFICA, 8., 2018, São Paulo. Anais [...]. São Paulo, SP: BIOgraph, 2018. Tema: Pesquisa (auto)biográfica, mobilidades e incertezas: novos arranjos sociais e reconfigurações identitárias.

KOTRE, J. Luvas brancas. Como criamos a nós mesmos através da memória. Trad. Flávia Villas-Boas. São Paulo, SP: Mandarim, 1997.

LIÁÑEZ, A. J. C. Pasión y temor de Dios de una mujer puritana: carta de Susana Bell en lecho de muerte. In: CHACÓN, M. L. C. Pasiones en femenino. Europa y América, 16001950. Sevilla, Espanha: Editorial Universidad de Sevilla, 2019.

LÓPEZ CARRETERO, A. Ensinar o ofício de ensino: um ofício da alma. Revista IberoAmericana de Estudos em Educação, Araraquara, v. 14, n. 3, p. 917-927, 2019. Disponível em: https://periodicos.fclar.unesp.br/iberoamericana/article/view/11121/8141. Acesso em: 07 jan. 2021.

LORIGA, S. O pequeno x. Da biografia à história. Belo Horizonte, MG: Autêntica, 2011. 
PEÑARROCHA, M. F. Experiencias subjetivas de las estrategias familiares: una aproximación a la vida cotidiana desde la historia de la familia. In: FERNÁNDEZ, M. G. Cultura material y vida cotidiana moderna: escenarios. Madrid, Espanha: Sílex, 2013.

PRADO JÚNIOR, C. Introdução. In: BARROS, M. P. No tempo de dantes. São Paulo, SP: Paz e Terra, 1998. p. 13-15.

ROUSSO, H. A última catástrofe: a história, o presente, o contemporâneo. Rio de Janeiro, RJ: Editora FGV, 2016.

VASCONCELOS, M. C. C. A casa e seus mestres. A educação no Brasil de oitocentos. Rio de Janeiro, RJ: Gryphus, 2005.

VASCONCELOS, M. C. C. Ensinamentos e contos: Maria Amália Vaz de Carvalho e sua estratégia para a educação da mulher. Revista Diálogo Educacional, Curitiba, v. 20, n. 67, p. 1513-1538, out./dez. 2020. Disponível em:

https://periodicos.pucpr.br/index.php/dialogoeducacional/article/view/27363/24582. Acesso em: 20 dez. 2020.

VASCONCELOS, M. C. C. Preceptoras estrangeiras para educar meninas nas casas brasileiras do século XIX. Cadernos de História da Educação, Uberlândia (MG), v. 17, p. 285-308, 2018. Disponível em: http://www.seer.ufu.br/index.php/che/article/view/43282. Acesso em: 05 jan. 2021.

\section{Como referenciar este artigo}

VASCONCELOS, M. C. C.; GOMES, E. V. Práticas educativas femininas nas memórias de Maria Paes de Barros. Revista Ibero-Americana de Estudos em Educação, Araraquara, v. 16, n. esp. 3, p. 1422-1438, jun. 2021. e-ISSN: 1982-5587. DOI: https://doi.org/10.21723/riaee.v16iesp.3.15290

Submissão em: 05/02/2021

Revisões requeridas em: 30/03/2021

Aprovado em: 12/05/2021

Publicado em: 01/06/2021 